\title{
Usos da língua tupi entre os Potiguara: qual Política Linguística em foco?
}

\author{
Hellen Cristina Picanço Simas ${ }^{1}$ \\ Regina Celi Mendes Pereira da Silva²
}

Resumo: Decorridos dezessete anos de implantação da língua tupi nas escolas potiguaras do estado da Paraíba, ainda se faz necessária uma reflexão para avaliar e compreender os impactos dessa ação na comunidade. Assim, neste artigo, fruto de uma pesquisa maior, de caráter qualitativo e etnográfico, traçamos um delineamento do que entendemos por Política Linguística (PL) e discutimos as implicações dessa política linguística na comunidade potiguara à luz dos estudos de D’Angelis (2015), Morello (2017), Cruz (2011) e Rodrigues (2002). Os resultados indicam que não houve avanços significativos nos usos da língua tupi, restringindo-se à escola, enquanto língua objeto de ensino aprendizagem; e o registro situado de algumas palavras em tupi na fala de alunos e professores, em cartazes específicos na escola e em alguns lugares públicos da aldeia.

Palavras-chave: Língua Tupi. Povo Potiguara. Política Linguística.

Abstract: After seventeen years of implantation of Tupi language in the Potiguara schools of the state of Paraíba, a reflection is still needed to evaluate and understand the impacts of this action in the community. Thus, in this article, the results, based on a larger research, of qualitative and ethnographic character, we draw an outline of what we understand by linguistic policy (PL) and we discuss the implications of this linguistic policy in the Potiguara community in the light of the studies of D'Angelis (2015), Morello (2017), Cruz (2011) and Rodrigues (2002). The results indicate that there were no significant advances in the uses of Tupi language, restricting to the school, as a language object of teaching learning, the local use of a few words in Tupi in the speech of students and teachers, in specific posters in the school and in some public places of the village.

Key-words: Tupi language. Potiguara people. Linguistic Policy.

Resumen: Después de diecisiete años de implantación de la lengua tupí en las escuelas potiguaras del estado de Paraíba, todavía se hace necesaria una reflexión para evaluar y comprender los impactos de esa acción en la comunidad. En este artículo, fruto de una investigación mayor, de carácter cualitativo y etnográfico, trazamos un delineamiento de lo que entendemos por Política Lingüística (PL) y discutimos las implicaciones de esa política lingüística en la comunidad potiguara a la luz de los estudios de D'Angelis (2015), Morello (2017), Cruz (2011) y Rodrigues (2002). Los resultados indican que no hubo avances significativos en los usos de la lengua tupí, restringiéndose a la escuela, como lengua objeto de

1 Professora Adjunto III do Instituto de Ciências Sociais, Educação e Zootecnia (ICSEZ), da Universidade Federal do Amazonas. Membro da Pós-Graduação em Educação (PPGE/UFAM).

2 Professora da Universidade Federal da Paraíba (UFPB) e Professora do Programa de PósGraduação em Linguística (PROLING/UFPB). 
enseñanza aprendizaje; y el registro situado de algunas palabras en tupi en el habla de alumnos y profesores, en carteles específicos en la escuela y en algunos lugares públicos de la aldea.

Palabras clave: Lengua Tupi. Pueblo Potiguara. Política Lingüística.

\section{Introdução}

Os potiguara formam uma população de 18.445 (SIASI/SESAI, 2014), distribuídos em três terras indígenas (Potiguara, Jacaré de São Domingos e Potiguara Monte-Mor). Possuem 32 aldeias, localizadas entre três municípios paraibanos: Marcação, Rio Tinto e Baía da Traição. Autodenominam-se Potiguara, comedores de camarões. Possuem festas populares em celebração a santos católicos, mas também praticam o ritual Toré, principalmente, em situações de celebrações do dia do indígena e quando ganham lutas em prol de suas causas.

Este povo foi um dos primeiros nativos a ter contato com os europeus em idos dos anos 500, e a sobreviver ao extermínio físico e cultural sofrido pelos povos indígenas. Sempre em luta, elegeram, em 1992, a primeira prefeita indígena do Brasil: Iracy Cassiano Soares (PMDB), para governar o município de Baía da Traição. Há 20 anos criaram o movimento Retomada e, por meio dele, conseguiram que as escolas presentes em suas aldeias se tornassem escolas específicas, diferenciadas e bilíngues. Através desse movimento indígena, surgiu a política linguística (PL) em prol da implantação da língua tupi, que teve como uma de suas ações de destaque tornar a língua indígena disciplina obrigatória na grade curricular das escolas potiguaras.

Assim, decorridos dezessete anos da implantação do tupi nas escolas indígenas potiguara, faz-se necessário refletir sobre os resultados alcançados e os desafios de tentar tornar uma comunidade indígena monolíngue em língua portuguesa em bilíngue em língua portuguesa e tupi. O presente artigo, portanto, visa discutir e avaliar a política de implantação da língua tupi na comunidade do povo potiguara, no estado da Paraíba.

Nessa direção, inicialmente apresentamos a nossa compreensão do que é uma política linguística, a filiação genética da língua tupi e, por fim, discutiremos a política linguística de implantação da língua tupi junto ao povo potiguara, apontando as dificuldades e fragilidades no processo. Esperamos fomentar a discussão no campo dos 
estudos das línguas em contato, educação escolar indígena e política linguística para as línguas de povos nativos.

\section{Políticas linguísticas: conceitos e tipos}

A partir do reconhecimento da diversidade linguística do Brasil pela Carta Magna de 1988, muitas ações dos governos federais, estaduais e municipais têm sido promovidas no intuito de implantar e desenvolver políticas linguísticas em prol das línguas indígenas brasileiras. Também no contexto acadêmico, o tema ganhou espaço nas discussões com a formação de grupos de estudos e pesquisadores no país.

As primeiras discussões sobre Política Linguística e Planejamento Linguístico foram se configurando a partir da segunda metade do século XX (CALVET, 2007). Especificamente, as reflexões iniciais surgiram em 1959, no trabalho de Einar Haugen, intitulado Planning in Modern Norway in Antropological Linguistics, usado pelo autor para tratar dos problemas linguísticos da Noruega. Em 1964, Haugen tratou também do tema Política Linguística em um evento na Universidade da Califórnia, que resultou na obra Linguistics and Language Planning, organizada por William Bright.

Em 1968, uma obra coletiva de Fishman, Ferguson e Das Gupta foi publicada sob o título de Language Problems of Developing Nations, a qual tratou novamente dos temas Política Linguística e Planejamento Linguístico, especificamente sobre os problemas linguísticos dos países em desenvolvimento. Em 1971, foi a vez de Joan Rubin e Bjorn Jernudd organizarem a obra Can Language be Planned? Dentre os autores que contribuíram com a reflexão, destacam-se Einar Haugen, J. Rubim, J. Das Gupta, B. Jernudd, J. Fishman e C. Ferguson.

Modernamente, Louis-Jean Calvet (2007), ao discutir a origem das Políticas Linguísticas, apresenta tipologia das situações plurilíngues, mostra como são executados planejamentos linguísticos e exemplifica as políticas de corpus e de status, no livro Políticas Linguísticas. Calvet (2007, p. 11) define Política Linguística como a “determinação das grandes decisões referentes às relações entre línguas e a sociedade” 
(CALVET, 2007, p. 11), enquanto Planejamento Linguístico seria a implementação da política linguística (CALVET, 2007, p. 11). Isto é, define-se como Política Linguística a tentativa de intervir na língua, na sua forma, bem como no seu uso padrão, escolhendo e impondo uma forma de uso, geralmente, essa tentativa parte da minoria em direção à maioria dos membros de uma comunidade linguística; por sua vez, o que se refere às ações que tornam essas decisões políticas praticáveis, caracterizam o Planejamento Linguístico.

Haugen (1966 apud CALVET, 2007, p. 22) trouxe para o cenário de estudo da Política Linguística conceitos oriundos da administração e da economia, objetivando entender a intervenção do Estado sobre as línguas. Por isso, fez uso da teoria da decisão, de Herbert Simon para analisar as Políticas Linguísticas, apontando as quatro fases: 1 - diagnóstico de um problema; 2 - concepção das soluções possíveis; 3 - escolha de uma decisão e 4 - avaliação da solução tomada. O autor aponta ainda que o Planejamento Linguístico passa por procedimentos de decisões que envolvem os decisores (os falantes), ou seja, aqueles que possuem poderes suficientes para orientar e controlar a mudança linguística, o uso diversificado da língua.

Seguindo a mesma vertente formalista com relação à Política Linguística, Punya S. Ray e V. Tauli pensam a Política Linguística como uma forma de aperfeiçoar e padronizar a língua através da intervenção na sua escrita, gramática e léxico. "Uma vez que a língua é um instrumento, isso significa que uma língua pode ser avaliada, alterada, corrigida, regulada, melhorada e novas línguas podem ser criadas à vontade” (TAULI, 1968, p. 605).

Ao longo das décadas de sessenta e setenta, Luis Aracil (1965), depois em 1971, Robert Lafont e em 1981, Lambert-Félix Prudent passaram a introduzir concepções diferentes com relação à Política Linguística. Integrantes do grupo nomeado sociolinguística nativa, os autores afirmavam que entre as variedades linguísticas, havia uma situação conflituosa em que sempre a língua dominada termina desaparecendo ou, por outro lado, pode adquirir novo status, igual ou superior ao da língua dominante. Tais situações vão depender da Política Linguística escolhida pelo país.

No Brasil, os estudos começaram em 1960, objetivando discutir a implicações entre o poder e as línguas, ou seja, refletir sobre como as grandes decisões políticas implicam sobre as línguas e seus usos na sociedade (MONSERRAT, 2006). 
Wilmar D’Angelis é um dos pesquisadores brasileiros que tem se debruçado ao longo dos anos sobre o tema política linguística. Para o autor, todas as línguas indígenas no Brasil são minoritárias, por estarem seriamente ameaçadas de extinção, sem exceção. D’Angelis se opõe às tipologias de Wurm (1998), segundo o qual as línguas são classificadas em:

i) Línguas potencialmente ameaçadas: se as crianças começam a falar preferindo a língua dominante e aprendem imperfeitamente a língua obsolescente;

ii) Línguas ameaçadas: se os falantes mais novos são adultos jovens, e não há nenhuma (ou são poucas) crianças falantes;

iii) Línguas seriamente ameaçadas: se os mais novos falantes são de meiaidade, ou além de meia-idade;

iv) Línguas moribundas: se há somente alguns poucos falantes mais velhos restantes e

v) Línguas extintas: não existem mais falantes (D’ANGELIS, 2011, p. 6).

D’Angelis (2011), a partir dos estados ou estágios de vitalização versus perda linguística, propõe as seguintes tipologias para as línguas: i) Línguas vivas e plenamente ativas: são empregadas no cotidiano da vida das pessoas nas diversas situações de comunicação e para todas as finalidades comunicativas; ii) Línguas vivas, com perda de falantes: sofrem processo, em andamento, de restrição do espaço; iii) Línguas vivas apenas nas gerações mais velhas: os jovens e crianças se tornaram monolíngues em português, por exemplo; iv) Línguas mortas (com ou sem lembrantes): utilizadas apenas no ensino e em momentos rituais (celebrações, festas, teatro, atividades religiosas etc.) e abandonadas no uso cotidiano pelos membros da comunidade e v) Línguas desaparecidas: existiram, porém, não deixaram registros ou há apenas dados incipientes delas, por exemplo: Oti-Xavante (SP) e Mura (AM).

D’Angelis (2011) aponta que há, para cada situação linguística citada, uma política linguística adequada, sendo elas:

Fortalecimento e modernização: indicada para línguas vivas plenamente ativas, cujas ações podem ser desenvolvimento da escrita, inclusão em múltiplas mídias, ensino como $1^{\text {ax }}$ língua, produção de materiais didáticos e criação de Instrumentos Linguísticos. O processo de modernização envolve duas etapas:

(a) a renovação e ampliação lexical indispensável para lidar com novas situações, contextos, relações, tecnologias etc.; (b) o emprego da língua 
em questão nas interações sobre qualquer temática" (D’ANGELIS, 2011, p. 15).

Revitalização e Modernização: indicada para línguas vivas com perda de falantes, cujas ações devem ser voltadas para o desenvolvimento da escrita, ensino como $1^{\underline{\underline{a}}}$ e como $2^{2} \underline{\underline{a}}$ língua e produção de materiais didáticos.

Recuperação e Revitalização: indicada para línguas vivas apenas entre os mais velhos, cujas ações devem ser voltadas para criação de língua mista ou registro e documentação, ensino como $2^{\underline{a}}$ língua e produção de materiais didáticos. Revitalização só pode ser aplicada a comunidades que ainda possuem um número significativo de falantes e "diz respeito à reversão de um processo de declínio linguístico em curso ou, em outras palavras, à reversão de um processo de mudança (ou troca) linguística” (D'ANGELIS, 2011, p. 15).

Re-introdução de Bilinguismo: indicada para línguas mortas, cujas ações podem ser de Ressurreição ou Criação de língua mista ou Adoção de (outra) Língua ou Criação artificial de língua ou Ensino como 2ª língua e Produção de materiais didáticos;

Introdução de Língua Indígena: indicada para línguas desaparecidas, cujas ações devem ser voltadas ao processo de Ressurreição ou Criação de língua mista ou Adoção de (outra) Língua ou Criação artificial de língua ou Ensino como 2a língua e Produção de materiais didáticos.

O processo denominado ressurreição ocorre quando ações são pensadas para que uma língua morta, mas ainda não desaparecida, seja por existirem alguns lembrantes ou porque existem registros escritos ou gravados dela, volte a ter vida. Processo complicado, mas que deu certo para três línguas: Hebraico em Israel, Kernowek (língua céltica na Grã-Bretanha) e língua australiana Kaurna.

Por outro lado, o processo de criação de língua mista ocorre, por exemplo, quando existe a simplificação da sintaxe de uma língua devido a influências de outra língua, como ocorreu com a língua Kaingang que sofreu drástica simplificação sintática, com claras influências do Português. Boretzky e Igla (1994, p. 62) apontam que línguas mistas ocorrem no "estágio entre o bilingüismo e a troca de língua, quando os falantes, como grupo todo, não são mais completamente bilíngües, mas ainda não atingiram a completa mudança de língua”. 
Já o processo de adoção de outra língua indígena dá-se quando a comunidade indígena monolíngue em português decide aprender uma língua nativa diferente da sua língua ancestral, possivelmente morta ou desaparecida. Por exemplo, os Baré (AM) adotaram a língua nheengatu no lugar da sua língua morta baré.

O processo de criação de língua artificial, por sua vez, é produto do trabalho intelectual das pessoas, a exemplo da língua Patxohã do povo Pataxó do Sul da Bahia, cujo vocabulário é formado pela reunião de palavras de várias línguas da região (D'ANGELIS, 2011).

D’Angelis (2011, p. 6) entende ainda que "a vitalidade das línguas minoritárias é a atitude dos falantes com respeito a ela e à língua majoritária, o que se pode traduzir por 'atitudes linguísticas' dos membros da comunidade minoritária”, bem como determinada pela condição socioeconômica da comunidade falante e pela tradição de escrita. O autor compreende que "línguas que são eleitas, pelas respectivas comunidades falantes, como marca efetiva de identidade grupal ou étnica têm maior vitalidade e condições de sobrevida" (D’ANGELIS, 2011, p. 6).

Tratar da questão "implica ao mesmo tempo uma abordagem científica das situações sociolinguísticas, a elaboração de um tipo de intervenção sobre as situações e os meios para se fazer essa intervenção" (CALVET, 2007, p. 19). Isto é, pesquisas devem acontecer, a fim de retratar a realidade de comunidades indígenas, de comunidades imigrantes e comunidades surdas a fim de entendermos se vivem uma realidade de bilinguismo, multilinguismo ou mesmo perda linguística.

Portanto, traçar projetos de ressurreição, revitalização, manutenção ou fortalecimento linguístico depende de ações que envolvam mais do que uma Educação Bilíngue e Intercultural e a produção de material didático em língua nativa, gramáticas e dicionários. Envolve ações conjuntas entre os governos Federal, Estadual e Municipal, a fim de promover projetos de conscientização das comunidades que mantêm ainda o uso da língua nativa, para não deixar a Língua Portuguesa avançar dentro da comunidade e, ao mesmo tempo, criar contextos para uso da escrita das línguas indígenas como forma de substanciar seu uso. Em comunidades que estão deixando de usar a língua nativa, é necessária uma intervenção para revitalizar os seus usos e, nas outras em que não se fala mais língua indígena, são necessárias a reflexão e discussão com a comunidade a fim de decidir sobre a implantação ou não de uma 
língua indígena. A tomada de uma decisão coletiva também é uma ação de política linguística, pois a política linguística deve produzir transformações tanto no âmbito individual como no coletivo (HAMEL, 1988). "A escola, sozinha, não consegue, infelizmente, reverter tendências sociolinguísticas" (MAHER, 2007, p. 106).

\section{Língua Tupi/Tupinambá: filiação linguística e motivos de implantação na escola indígena Potiguara}

A língua tupi originariamente chamava-se língua tupinambá, foi a mais falada na costa brasileira no século XVI. Pertence à família-linguística tupi-guarani do tronco tupi e foi também designada pelos nomes: "língua do Brasil”, "língua da terra”, "língua do mar" e, principalmente, "língua brasílica" (RODRIGUES, 2004). A designação "língua tupinambá" aparece somente no século XVIII e "tupi" no século XIX (RODRIGUES, 2010).

No entanto, popularmente, recebe a nomeação equivocada de tupi-guarani, conforme destaca Tibiriça (1984, p. 11):

Outro fato a esclarecer é que fala-se às vezes numa língua tupi-guarani sem que se saiba o que isto significa. O Tupi-guarani diz respeito ao tronco étnico, do mesmo modo que nos referimos ao indo-europeu, frígio-armênio etc. Tupiguarani, ou Macro-tupi, como estabelece o Instituto 'Bernadino Sahagun', é um conjunto de dialetos falados em quase todos os países da América do Sul. Portanto, falar de um certo idioma tupi-guarani, não tem propósito.

O tronco tupi a que a língua tupinambá pertence tem dois grandes ramos: o Oriental e o Ocidental. O ramo oriental é composto pelas famílias Puroborá, Ramarama, Mondé, Arikém e o ramo ocidental é composto pelas famílias Juruna, Tupari, Munduruku, Maweti-Guarani que, segundo Rodrigues e Dietrich (1997), se subdivide nas famílias Sateré-Mawé e Aweti-Tupi-Guarani, que depois se subdivide, mais uma vez, em Aweti e Tupi-Guarani. Para os citados autores, a família TupiGuarani é subgrupo da família Aweti-Tupi-Guarani. Drude (2006) entende que não houve mudanças linguísticas significativas entre mawé, aweti e Proto Tupi-Guarani, 
logo, a separação entre elas foi simultâneas ou muito próximas, opondo-se à hipótese de Rodrigues e Dietrich (1997).

A família Tupi-Guarani é a maior família do tronco Tupi, sendo classificada em oito ramos:

Figura 2: Família Tupi-Guarani

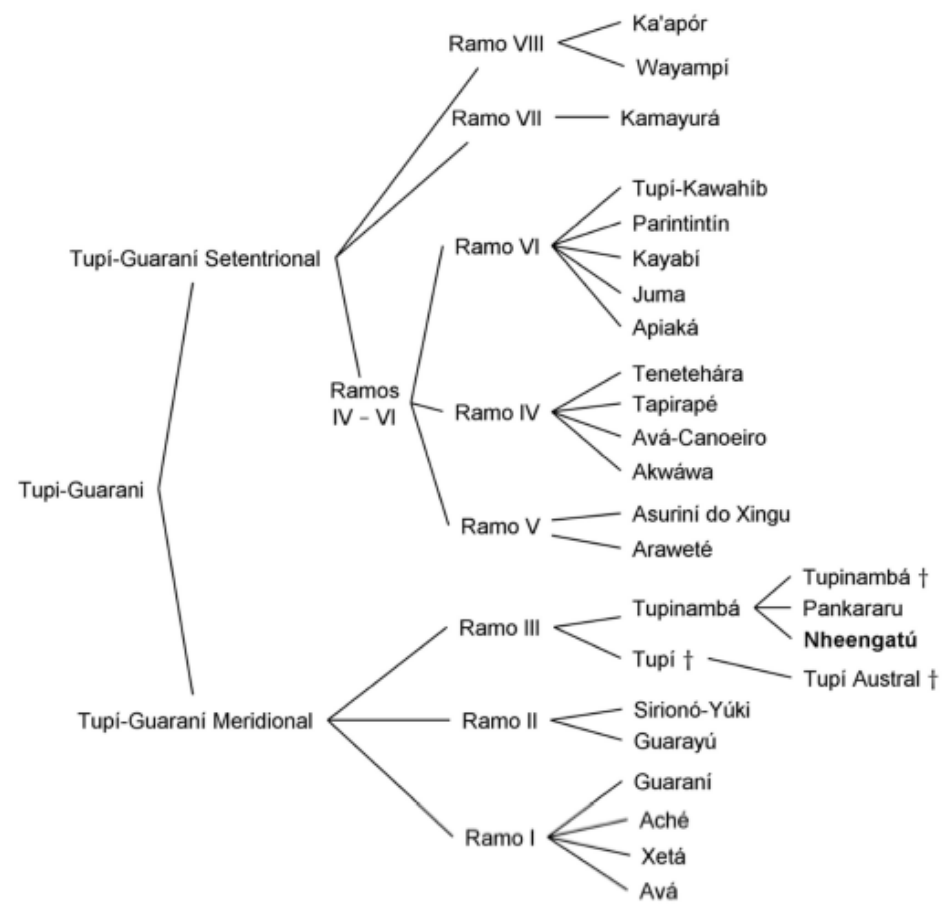

Fonte: Cruz (2011, p. 29)

A língua Tupinambá faz parte do ramo III, nomeado de Tupi-Guarani Meridional. O Tupi-Austral também é conhecido como a Língua Geral Paulista (LGP), língua originada "a partir do Tupiniquim, na região de São Paulo, e posteriormente levada ao Rio Grande do Sul, Cuiabá e Minas Gerais pelos bandeirantes” (CRUZ, 2011, p. 27), mas "no século XIX já havia deixado de existir" (FREIRE, 2004, p. 53). Enquanto a LGP desapareceu completamente, a língua Tupinambá deu origem à Língua Geral Amazônica (LGA), também nomeada Nheengatu, falada atualmente por grupos indígenas da região Amazônica, como os Baré, Baniwa, Warekena. Segundo Cruz (2011, p. 28-29), essa mudança passou pelas seguintes fases:

- Tupinambá - língua falada na costa do Brasil, no século XVI. 
- Língua geral brasílica - língua geral falada na província de Maranhão e GrãoPará, de 1616 até o final do século XVIII;

- Nheengatu - variedades de línguas gerais faladas na região amazônica no século XIX até o momento atual.

Antes de se falar em Nheengatu (língua boa), houve um momento em que a nomeação língua geral perdurou. Atualmente, segundo Cruz (2011), alguns falantes de Nheengatu usam o termo língua geral de forma pejorativa para classificar a língua falada por aqueles que misturam a Língua Portuguesa e a Nheengatu. Assim, o próprio termo Nheengatu se tornou marca de afirmação de identidade indígena, sendo aquele que não a domina bem colocado no grupo dos que falam língua geral, podendo ser entendido como o que não tem língua definida ou mesmo identidade definida.

Mattoso Câmara (1979, p. 101) sustenta a hipótese de que a língua tupinambá foi modificada pelos jesuítas: “o TUPI que as primeiras exposições dos europeus nos forneceram não é exatamente aquele que os indígenas falavam: é uma sistematização simplificada, feita para se proceder à propaganda religiosa dentro do ambiente indígena”.

Os tupinólogos tiveram como objetivo, consciente ou inconscientemente, não apenas estudar, mas, sobretudo, "aperfeiçoar" a língua tupi para ela se parecer com o ideal da gramática ocidental, ou seja, o missionário e o estudioso não descreveram como a língua tupinambá era, mas como deveria ser, criando uma língua imaginária, a qual influenciou a língua real, pois a moldou (ORLANDI, 1988). José de Anchieta foi o primeiro a estudar o tupinambá e descrever sua gramática na obra Arte de Gramática da Língua mais Usada na Costa do Brasil, em 1595.

Entendemos, no entanto, que não foram os jesuítas especificamente que modificaram a língua tupinambá, transformando-a no tupi jesuítico, mas a língua modificou-se naturalmente devido ao processo de transformação pelo qual qualquer língua passa quando em situação de contato. Falar que os jesuítas modificaram a língua é colocar o indígena, mais uma vez, numa posição inferior, de sujeito passivo que recebe uma língua mais fácil do branco, ao invés de compreendê-lo também como sujeito ativo no processo de mudança linguística. Logo, mesmo que ele tenha sido 
obrigado a modificar sua forma de atuação verbal, atuou no jogo de reorganização da língua tupinambá.

Os potiguara eram falantes do tupinambá, no entanto, segundo Palitot (2005, p. 250), constitui-se, há, pelo menos, 250 anos, como grupo indígena monolíngue em Língua Portuguesa. Todavia, atualmente há nas escolas indígenas potiguara o ensino da língua tupi, não da língua Tupi, da qual se originou o Tupi-Austral, mas da língua tupi como referência à língua tupinambá. Os indígenas chamam-na de língua tupi devido ao curso que fizeram de Tupi Clássico, ministrado pelo professor da Universidade de São Paulo (USP), Eduardo de Almeida Navarro. A partir deste estudo, adotaram essa nomenclatura em referência a sua língua ancestral e passaram a usá-la para nomear a disciplina língua indígena implantada no currículo da escola potiguara. Em seguida, discorremos sobre a política de implantação da língua tupi nesta comunidade.

\section{Política linguística de reconstrução da língua tupi: potencialidades e fragilidades}

\subsection{Motivações para política linguística em prol da língua tupi}

Há 17 anos, os Potiguara decidiram implementar uma política linguística em prol da implantação da língua indígena tupinambá, chamada por eles de tupi. Logo, a língua que os potiguara decidiram aprender ou reaprender não é o chamado Tupi Moderno que corresponde ao Nheengatu ou Língua Geral Amazônica, mas a língua imaginária (ORLANDI, 1988), criada pelos jesuítas (CÂMARA, 1979), ou seja, língua criada pelos religiosos e estudiosos a partir dos seus conhecimentos linguísticos, não foi descrita a língua real falada pelos indígenas. Nomearam o processo de retomada da língua tupi. Vejamos a distinção que Eduardo Navarro faz entre algumas nomenclaturas-chave à discussão do tema em estudo: 
TUPI ANTIGO - Essa foi a língua que os marinheiros da armada de Cabral ouviram quando aqui chegaram em 1500 e que ajudou na construção espiritual do Brasil. Naquela época, essa língua era falada em toda a costa do Brasil por muitos grupos indígenas: os Potiguaras, os Caetés, os Tupinambás, os Temiminós, os Tabajaras, etc. Seu primeiro gramático foi o Padre José de Anchieta, que publicou sua Arte de Gramática da Língua mais Usada na Costa do Brasil, em 1595 (NAVARRO, 2012, p. 3).

LÍNGUA GERAL - Foi uma língua surgida da evolução do Tupi Antigo, a partir da segunda metade do século XVII, quando, então, era falada por todos os membros do sistema colonial brasileiro: negros, brancos, índios tupis e não tupis, mestiços (NAVARRO, 2012, p. 3).

NHEENGATU - é uma língua da Amazônia, uma evolução da língua geral, falada por caboclos no vale do Rio Negro, na Amazônia. É uma fase atual do desenvolvimento histórico do Tupi Antigo, mas não é o Tupi Antigo (NAVARRO, 2012, p. 3).

TUPI MODERNO - é o nome que alguns dão ao Nheengatu da Amazônia ou, ainda, a certas línguas faladas da família Tupi-Guarani. Não é a língua que Anchieta estudou, mas uma evolução dela (NAVARRO, 2012, p. 3).

TUPI-GUARANI - não é uma língua, mas uma família de mais de vinte línguas. Inclui o Tapirapé, o Wayampi, o Kamayurá, o Guarani (com seus dialetos), o Parintintin, o Xetá, o Tupi Antigo, etc. Existem línguas TupiGuarani, não o Tupi-Guarani. Dessas, o Tupi Antigo é a que foi estudada primeiro e a que mais influenciou a formação da cultura brasileira (NAVARRO, 2012, p. 3).

A decisão de aprender a citada língua indígena e reintroduzir o bilinguismo na comunidade potiguara se deu muito pela pressão da sociedade que exige que o indígena fale sua língua ancestral para ser reconhecido como tal e pelo desejo de recuperarem parte da identidade potiguara perdida durante o processo colonizador. Por isso, solicitaram da Secretaria de Educação Escolar Indígena da Paraíba cursos de língua tupi para os professores indígenas serem os primeiros a aprenderem a língua nativa. Em seguida, esse grupo de professores foi o disseminador da língua nas escolas entre os alunos e, de forma geral, na comunidade potiguara. A língua Tupi aparece ou reaparece, no contexto potiguara, a partir de um curso de formação de professores indígenas, ministrado pelo professor da Universidade de São Paulo, Eduardo Navarro, em 200o. O curso nomeado Tupi Clássico teve a duração de dois anos, formando 17 monitores bilíngues para atuarem como professores nas escolas potiguara, objetivando-se, assim, multiplicar o conhecimento sobre a língua Tupi e implementar o projeto nomeado por eles de resgate da língua ancestral dos potiguara. A partir de então, dois professores potiguara, Josafá Padilha Freire e Pedro Eduardo Pereira, 
juntamente com o professor Eduardo Navarro elaboraram cartilhas para ensino da língua tupi, e o governo do estado da Paraíba as publicou e as distribuiu nas escolas indígenas potiguara.

Embora o processo seja reconhecido na comunidade por resgate da língua Tupi, entendemos que o melhor termo para nomear a política linguística executada em prol da língua seja implantação da língua tupi, uma vez que os potiguara constituem-se como grupo indígena monolíngue em Língua Portuguesa há, pelo menos, 250 anos (PALITO, 2005) e sua língua é morta. Logo, não é possível resgatar, pois precisaria existir, pelo menos, um grupo de falantes vivo. O que efetivamente ocorre é a implantação de uma língua indígena na comunidade potiguara ou, como afirma Wilmar D’Angelis (2011), a tentativa de ressuscitar uma língua morta.

\subsection{Institucionalização da língua tupi, promoção de seus usos e âmbito de circulação}

A Secretaria de Educação Escolar Indígena da Paraíba institucionalizou a língua tupi no currículo das escolas indígenas, realizando a política linguística de status da língua tupi. Segundo Morello (2017), a institucionalização da língua indígena é de suma importância:

As ações visando à institucionalização dos usos da língua não somente legitimam as normas acordadas, como criam novos lugares para a língua, fomentando as práticas bilíngues no âmbito da gestão das políticas públicas, com consequência na formação e preparação profissional dos cidadãos (MORELLO, 2017, p. 234).

A disciplina língua tupi é ministrada desde os anos iniciais até o ensino médio, com 25 horas-aula. O âmbito de circulação é restritamente o escolar e durante a realização do ritual toré, momento em que são cantadas músicas traduzidas para o tupi. Situação linguística que aponta o tupi na condição de língua morta (D’ANGELIS, 2011).

A investigação linguística e a documentação da língua foram realizadas pelo pesquisador Eduardo Navarro, especialista em tupi antigo e autor do livro Método moderno de tupi antigo e do dicionário Tupi antigo. 
O planejamento de execução da política linguística de implantação do tupi ou de ressurreição dessa língua se manteve estagnado até 2018, quando, novamente, o professor Eduardo Navarro voltou a ministrar um curso de formação em língua tupi para professores potiguara, em solicitação à Secretaria de Educação do Estado da Paraíba. Na oportunidade, realizou-se uma avalição da língua tupi e prestou-se homenagem à primeira turma de professores formada e pelos trabalhos prestados em todos esses anos, como disseminadores do ensino da língua indígena nas escolas potiguaras.

Atualmente há dois cursos de língua tupi acontecendo: um pela Secretaria de Educação municipal de Baía da Traição, destinado somente a professores da rede municipal; outro pela Universidade Federal da Paraíba (UFPB), aberto ao público geral.

Assim, diagnosticamos o uso da língua tupi nos seguintes termos: usada como língua objeto de ensino nas escolas, com uso restrito de palavras na fala, principalmente entre jovens de até 15 anos de idade, ou seja, o domínio incide sobre o léxico da língua, sem estabelecer uma interação verbal efetiva, mas utilizam algumas palavras em tupi no dia a dia da escola. Em relação ao uso do tupi na escrita, restringese principalmente a cartazes colocados nas escolas. Dessa forma, verifica-se que não houve promoção da língua tupi para ela circular nos diversos contextos sociocomunicativos, a exemplo das interações em redes sociais, ambiente familiar, comercial, profissional etc.

\subsection{Fragilidades da política linguística em prol da língua tupi}

Apontamos algumas ações que, no nosso entendimento, seriam necessárias para reconstruir/ressuscitar a língua tupi:

i) A realização de oficinas para analisar a implementação da política linguística adequada à realidade da comunidade. No caso dos potiguara, eles optaram por ressuscitar sua língua ancestral, mas poderiam ter escolhido adotar uma língua indígena como a nheengatu, que é originária da língua tupi e ainda possui muitos falantes. Talvez tivesse sido mais fácil tornar a comunidade potiguara 
bilíngue se a política linguística tivesse sido a de adoção da língua indígena nheengatu, uma vez que poderia haver interação entre os potiguara e os indígenas da região norte que falam o nheengatu, a exemplo dos tukano, baré e baniwa. As redes sociais seriam ferramentas interessantes nesse processo interativo, pois criariam contextos de comunicação para a promoção da língua indígena e do bilinguismo do povo potiguara, como descreve Morello (2017) ao tratar da língua guarani:

\begin{abstract}
Em um trabalho liderado pela Facultad Politécnica de la Universidad Nacional de Assunción, em parceria com o Ateneo de la Lengua y Cultura Guaraní, a Secretaría de Políticas Lingüísticas, o Instituto Superior de Lenguas de la UNA e a comunidad Mozilla Paraguay, essa frente culminou no desenvolvimento de uma interface em guarani, do Firefox para android6 recentemente lançado. O Firefox em guarani permite aceder e navegar pela internet, constituindo um instrumento fundamental de gestão e produção de conhecimentos nessa língua, além de democratizar seu acesso permitindo que falantes monolíngues em guarani compartilhem os recursos e os conhecimentos das redes digitais (MORELLO, 2017, p. 233).
\end{abstract}

Além do mais, existem ricos materiais de registro da língua nheengatu seja oral seja escrito, trabalhos de pesquisadores de nheengatu, o que poderia facilitar a realização de cursos de formação com mais frequência na comunidade potiguara.

ii) A realização sistemática de oficinas e seminários para impulsionar o aprendizado do uso oral e escrito da língua tupi. Somente um grupo de professores fez duas vezes o curso de tupi antigo, logo, eles não tiveram formação suficiente para aprender a língua indígena. Ressalta-se que esse tipo de atividade não dá garantias de aprendizado, mas não as ter é muito prejudicial, pois:

a falta gritante de uma política educacional voltada à melhor capacitação dos professores indígenas e à implantação de verdadeiros programas de ensino bilíngue nas escolas indígenas está contribuindo para o desaparecimento das línguas" (D’ANGELIS, 2014, p. 7).

No caso do tupi, a fragilidade da política educacional prejudica a ressuscitação da língua tupi. Ressalta-se que não é o ensino escolar o fator determinante para a comunidade potiguara se tornar bilíngue, uma vez que é a necessidade de uso social de uma língua que determina sua expansão dentro deum grupo linguístico. Além da atitude linguística dos falantes: "Línguas que são eleitas, pelas respectivas comunidades 
falantes, como marca efetiva de identidade grupal ou étnica têm maior vitalidade e mais chances de sobrevida" (D'ANGELIS, 2014, p. 4).

iii) O apoio para o desenvolvimento de planos e projetos que promovam o uso da língua tupi: sem um planejamento, qualquer política linguística falhará, visto que são necessárias ações para que a proposta escolhida possa ser efetivada. Entre os potiguara, é necessário pensar essas questões e traçar um plano de ação, do contrário o projeto inicial de tornar a comunidade bilíngue em português e língua indígena continuará estacionado.

\section{Considerações finais}

Esta pesquisa produz informações de base para o planejamento da política linguística de ressurreição da língua tupi ou até mesmo de mudança de política linguística. Após dezessete anos de implantação do tupi nas escolas potiguaras, não houve avanços significativos, considerando que a língua não ganhou vitalidade. É usada como língua objeto de estudo nas escolas; apenas algumas palavras são usadas, na oralidade, por alunos e professores e, na escrita, há registro em alguns cartazes nas escolas.

Três dificuldades de execução do planejamento linguístico fazem-se presentes: falta de formação continuada em tupi para professores potiguaras; falta de seminários e oficinas para o público geral conhecer a língua tupi e falta de planos e projetos que promovam a língua tupi nos variados contextos linguísticos.

Diante do exposto, compreendemos que há a necessidade do povo potiguara, repensar essa política linguística, estar atento à realidade de suas práticas, sob pena de que as metas de bilinguismo se tornem mais e mais distantes de serem alcançadas. 


\section{Referências}

BORETZKY, Norbert e IGLA, Birgit. 1994. Dialetos Mistos Romani. In: BAKKER, Peter e MOUS, Maarten (Eds.). Idiomas mistos: 15 estudos de caso em entrelaçamento de linguagem, 35-68. Amesterdão: IFOTT.

CALVET, Louis-Jean. As Políticas Linguísticas. São Paulo: Parábola, IPOL, 2007.

CAMARA JR., J. Mattoso. Introdução às Línguas Indígenas Brasileiras. Rio de Janeiro: Ao Livro Técnico, 1979.

CRUZ, Aline. Fonologia e Gramática do Nheengatú: A língua geral falada pelos povos Baré, Warekena e Baniwa. Tese de Doutorado, Vrije Universiteit Amsterdam, 2011.

D'ANGELIS, Wilmar. Recuperar, ressuscitar, adotar ou inventar? Povos indígenas em busca de (alg)uma língua. X Congreso Argentino de Antropologia Social, 2011.

. Línguas Indígenas no Brasil: urgência de ações para que sobrevivam. IX ELESI, 2014 .

Drude, Sebastian. 2006. On the position of the Awetí language in the Tupi family Em: Guaraní y "Mawetí-Tupí-Guaraní". Estudios históricos y descriptivos sobre uma familia lingüística de América del Sur, por Wolf Dietrich e Symeonidis Haralambos (orgs.). Berlim \& Munique: LITVerlag, 47-68.

FREIRE, José Ribamar Bessa. Trajetória de muitas perdas e poucos ganhos. In:

Educação Escolar Indígena em Terra Brasilis - tempo de novo descobrimento. Rio de Janeiro: Ibase, 2004. p. 11-31.

HAMEL, R. E. La política del lenguaje y el conflicto interétnico. Problemas de investigación sociolingüística. In: ORLANDI, E. (Org.). Política lingüística na América Latina. Campinas: Pontes, 1988.

MAHER, Terezinha. Do Casulo ao Movimento: a supressão das incertezas na educação bilíngüe e intercultural. In: CAVALCANTI, M. \& BORTONI-RICARDO, S.M. (Orgs.). Transculturalidade, Linguagem e Educação. Campinas, SP: Mercado de Letras, 2007. MORELLO, Rosângela. Língua Guarani: políticas linguísticas e pluricentrismo. In: MARTINS, Marci Fileti. (Org.). As línguas tupi faladas dentro e fora da Amazônia. Rio de Janeiro: Museu Nacional do Índio, 2017. 
MONSERRAT, Ruth Maria Fonini. Política e Planejamento Linguístico nas sociedades indígenas do Brasil hoje: o espaço e o futuro das línguas indígenas. In: GRUPIONI, Luíz Donisete Benzi (Org.). Formação de professores indígenas: repensando trajetórias. Brasília: Ministério da Educação, Secretaria de Educação Continuada, Alfabetização e Diversidade, 2006.

NAVARRO, Eduardo. Curso de Tupi. Disponível em: <http://www. fflch.usp.br/dlcv/tupi/artigo_2.html>. Acesso em: 14 set. 2012.

ORLANDI, Eni. Política Linguística na América Latina. Campinas: Pontes, 1988.

PALITOT, Estevão Martins. Os Potiguara da Baía da Traição e Monte- Mór: história, etnicidade e cultura. (Dissertação de mestrado) João Pessoa: 2005.

RODRIGUES, Aryon Dall'igna. Línguas Brasileiras: para o conhecimento das línguas indígenas. São Paulo: Loyola, 2002.

- As Línguas Brasileiras. In: MARIANI, Bethania. Colonização Lingüística: línguas, políticas e religião no Brasil (século XVI a XVIII) e nos Estados Unidos da América. Campinas: SP: 2004.

.Tupí, tupinambá, línguas gerais e português do Brasil. In: Volker Noll e Wolf Dietrich (orgs.). O português e o tupí no Brasil. São Paulo: Contexto, 2010,:27-47

Rodrigues, Aryon Dall'Igna, e Wolf Dietrich. On the relationship between Mawé and Tupi-Guarani. Diachonica, 1997, XIV, n. 2: 265-304.

SIASI/SESAI, 2014. In: SOCIOAMBIENTAL. Os potiguara. Disponível em: $<$ https://pib.socioambiental.org/pt/Povo:Potiguara\#Nome_e_1.C3.ADngua $>$ Acesso em: 13 set. 2018.

TAULI, V. Introduction to a Theory of the Ninth Congress of Linguistics - Cambridge, 1962. Haia: Mouton, 1968.

TIBIRIÇA, L. C. Dicionário Tupi - Português: com esboço de gramática de Tupi Antigo. São Paulo: Traço Editora, 1984.

WURM, Stephen. Methods of language maintenance and revival, with selected cases of language endangerment in the world. In K. Matsumara (ed.) Studies in endangered languages, 1998, p. 191-211. 
Recebido em 16/o9/2018.

Aprovado em 26/11/2018. 